\title{
Quality of life of Zambian breast cancer women receiving care at the cancer diseases hospital Lusaka
}

\author{
Masadza Wezzie ${ }^{1,2}$, Siankulu Elaine ${ }^{1,3}$, Kawalika Micheal ${ }^{1,4}$, Victoria Mwiinga-Kalusopa*1, Patricia Katowa-Mukwato ${ }^{1}$ \\ ${ }^{1}$ School of Nursing Sciences, University of Zambia, Zambia \\ ${ }^{2}$ Kasama Schools of Nursing, Northern Province, Zambia \\ ${ }^{3}$ Kawambwa District Hospital, Luapula Province, Zambia \\ ${ }^{4}$ Mpongwe Mission hospital, Copperbelt Province, Zambia
}

Received: April 18, 2019

Accepted: December 1, 2019 Online Published: June 8, 2020

DOI: $10.5430 /$ jnep.v10n9p57

URL: https://doi.org/10.5430/jnep.v10n9p57

\begin{abstract}
Background: Breast cancer is the most frequently diagnosed malignancy among women in the world with an estimation of 1.67 million new diagnoses worldwide in 2012 estimated at $25 \%$ of all cancers. In Zambia, breast cancer is the second most common cancer affecting women and accounts for $9 \%$ of all histologically proven cancers among patients admitted at the country's only Cancer Diseases Hospital Most of the patients receive multiple treatment modalities; Surgery, Chemotherapy, Radiation Therapy and Hormonal Therapy, each with its own long-term side effects with a potential to affect the women's functionality, self-image and sexuality consequently the general quality of life of these women.

Methods: A descriptive cross-sectional study design was used to investigate the Quality of Life (QoL) and factors influencing QoL among women with breast cancer receiving care at Zambia's only Cancer Diseases Hospital. A total of 130 breast cancer patients on treatment who were willing to participate in the study were selected using simple random sampling. Data was collected using the European Organization for Research and Treatment in Cancer Quality of Life Questionnaire (EORTCQLQ-C30) and its breast cancer supplementary measure (QLQ-BR23). The tool assessed QoL across the physical, role, cognitive, emotional, and social functioning and sexual function domains.

Results: Overall, just about half (52.5\%) of the 130 respondents had high Quality of Life. QoL which was measured by the EORTCQLQ-C30 under the five domains (Physical, role, emotional, cognitive and sexual functioning) was high in four out of the five which scored above the global mean score of 68. Only the emotional functioning domain scored (65) below the mean. Conversely, the symptom scale scored high on all the eight sub items of fatigue, nausea and vomiting, pain, dyspnea, insomnia, appetite loss, constipation and diarrhea which signified high symptom experience among respondents. Similarly using the breast cancer supplementary measure (QLQ-BR23), two out of the four functional subscales (body image and sexual functioning) score high than average while sexual enjoyment and future perspectives score low. On the symptom scale, three out of the four scales scored higher than averages, signifying high symptom experience. Demographic characteristics which had significant association with QoL were age $(p<.023)$, level of education $(p<.023)$ and financial status $(p<.000)$. Other factors that had significant association with QoL were type of treatment being received $(p<.023)$, the severity of condition $(p<.000)$, access to health care services $(p<.000)$ and social support $(p<.000)$.

Conclusions: A diagnosis of breast cancer and its subsequent treatment affects several facets of a woman's life ranging from physical, emotional, social and financial aspects consequently affecting the entire QoL. However the QoL varies and is influenced by a number of factors including age at diagnosis of cancer, level of education, financial status, type of treatment received, severity of the condition, access to health care facilities and social support. Therefore any intervention aimed at improving the QoL should be multidimensional.
\end{abstract}

Key Words: Quality of life, Breast cancer, Cancer treatment Zambia.

*Correspondence: Victoria Mwiinga-Kalusopa; Email: victoriakalusopa@ gmail.com; Address: School of Nursing Sciences, University of Zambia, 


\section{INTRODUCTION}

Breast cancer is the most frequently diagnosed malignancy among women in the world with an estimation of 1.67 million new diagnoses worldwide in 2012 representing about $12 \%$ of all new cancer cases and $25 \%$ of all cancers in women. ${ }^{[1-3]}$ Due to advances in detection and treatment, increasing numbers of women are diagnosed with and surviving breast cancer. ${ }^{[4]}$ In Zambia, breast cancer is the second most common cancer affecting women and accounts for 9\% of all histologically proven cancers among patients admitted at the country's own Cancer Diseases Hospital. ${ }^{[5,6]}$ Breast Cancer patients seen at $\mathrm{CDH}$ have increased from 3\% in 2006 to about $9 \%$ of all patients treated at the Hospital by December 2016. A diagnosis of breast cancer is a stressor to both the patient and the family caregivers, implying that if a diagnosis is a stressor then it affects the QoL of both the patient and family caregivers. ${ }^{[7]}$

Quality of Life is a subjective concept, defined as "an individual's perception of their position in life in the context of culture and value system in which they live and in relation to their goals, expectations, standards and concerns". ${ }^{[8]}$ According to Ibrahim et al., ${ }^{[9]}$ QoL encompasses perceptions of the positive and negative aspects of physical, emotional, social, economic and cognitive functioning as well as the negative aspects of somatic discomfort and other symptoms produced by the disease or its treatment. QoL is reported to be compromised in patients with chronic illness such as breast cancer on treatment, and alterations on QoL have been seen among breast cancer patients in both developed and developing countries. ${ }^{[3,10-12]}$ Domains like physical functioning, emotional and social ${ }^{[13]}$ and material well-being have been reported in the literature to predict the QoL of patients. ${ }^{[14]}$ The other factors that influence QoL are stage of disease, ${ }^{[10,11,15]}$ treatment modality, access to hospital materials, financial status, knowledge ${ }^{[9]}$ about the condition and treatment received, ${ }^{[16]}$ emotional support, community and social support, ${ }^{[7]}$ support from health care providers and severity of illness. ${ }^{[1]}$

In general, patients with breast cancer have a better outcome and longer survival after cancer diagnosis compared to women with other types of cancer. On the other hand, through early detection programs and more effective treatments, more women with breast cancer are surviving longer. ${ }^{[11,16]}$ However, breast cancer affects women's selfimage, and therefore, studies focusing on the quality of life are vital in women who are undergoing chemotherapy and have their breasts surgically removed. ${ }^{[7,16]}$

As indicated earlier, advances in detection and treatment have led to increasing numbers of women diagnosed with and surviving breast cancer respectively. ${ }^{[4]}$ In developing countries, survival rates remains around 50\%-60\% and patients are living longer. Therefore studying QoL has become important and is increasing becoming a focal point of cancer research and clinical interest. ${ }^{[4]}$ This study therefore aimed at assessing the QoL and factors influence quality of life among women with breast cancer receiving care at the $\mathrm{CDH}$.

\section{METHODS}

The study was conducted at the Cancer Diseases Hospital (CDH) a modern specialized tertiary hospital offering radiation therapy, chemotherapy and hormonal cancer treatments. The hospital serves as a national referral centre for all cancers nationwide; the catchment population comprises all 107 districts and 10 provinces of Zambia. A descriptive cross-sectional study design was used and 130 breast cancer patients on treatment who were willing to participate in the study were selected using simple random sampling. A descriptive cross sectional study design was selected for this study because it can suggest the presence of relationships among variables at a single point in time just like theory suggests. ${ }^{[17]}$ The study population consisted of all breast cancer patients aged 18 years and above who had been visiting $\mathrm{CDH}$ for treatment, at the time of data collection. All women with breast cancer stages I to IV, who underwent surgery, chemotherapy and radiotherapy treatment and gave consent were included in the study. Data was collected using the European Organization for Research and Treatment in Cancer Quality of Life Questionnaire (EORTCQLQ-C30) and its breast cancer supplementary measure (QLQ-BR23). The EORTC QLQ-C30 is a well-known instrument for measuring quality of life in cancer patients and contains 30 items that measures five functional scales, global quality of life and several cancer related symptoms. ${ }^{[18]}$ The QLQ-BR23 is a specific questionnaire containing 23 items measuring functioning and symptoms related to breast cancer. ${ }^{[18]}$ The data collection tool had 3 sections, (a) demographic data and (b) EORTC QLQ-C30 and (c) QLQ-BR23. The EORTC QLQ-C30 is a well-known instrument for measuring quality of life in cancer patients and contains 30 items that measures five functional scales (physical, role, cognitive, emotional, and social functioning), three symptom scales (fatigue, pain, and nausea and vomiting), a global health status/QoL scale, and a number of single items assessing additional symptoms commonly reported by cancer patients (dyspnea, loss of appetite, insomnia, constipation and diarrhea) and perceived financial impact of the disease. On the other hand, the QLQBR23 is a specific questionnaire containing 23 items measuring disease symptoms, side effects of treatment (surgery, chemotherapy, radiotherapy and hormonal treatment) body image, sexual functioning and future perspective) related to 
breast cancer. ${ }^{[18]}$ In addition, a structured socio-demographic questionnaire was used and it collected the following data: age, gender, level of education, occupation, place of residence, marital status, employment status, way of access to the hospital, medical characteristics (date of diagnosis, disease stage at the time of diagnosis and current treatments), and information on their disease. Data was analysed using Statistical Package of Social Science (SPSS) version 20.0. Frequencies and proportions were computed for demographic and other variables. A Chi-Square was used to test for statistical significance of the factors affecting the QoL of breast cancer patients. A p-value of 0.05 was set as an upper limit for determining significance of association. Statistical significance was calculated using the chi square test.

\section{RESUlts}

Table 1 shows the demographic characteristics of the respondents, the respondents were on surgery, chemotherapy and radiotherapy treatments, clients two weeks and one year into treatment were included in the study. About one third (36.2\%) were aged between 31 and 40 years, more than half $(52.3 \%)$ were married and majority $(97.7 \%)$ were Christians. In terms of education, $34.62 \%$ attained senior secondary level of education, $30.77 \%$ attained tertiary education. The economic status was mainly poor with $35.4 \%$ of respondents having a monthly income of less than K1000.00 (less than 100.00 US Dollar per month, and only $10 \%$ had an income of more than K5,000.00 (more than 500.00 US Dollar) per month.

Table 2 outlines factors that that were assumed to influence QoL of breast cancer patients. The factors ranged from prior knowledge about breast cancer, treatment received, duration of treatment and access to health services. Others were; stage of cancer, severity of disease symptoms, support from family and support from health personnel. Two thirds of the respondents either had little knowledge (46.2\%) or no knowledge $(21.5 \%)$ about breast cancer prior to diagnosis. Majority of the respondents (66.9\%) received chemotherapy, while $22(16.9 \%)$ received radiotherapy and $21(16.2 \%)$ had surgery performed. Half the number of respondents (50.0\%) had received treatment for a period of between one and six months, while $25.4 \%$ had received for less than one month and $24.6 \%$ for more than six months. most of the respondents $65.4 \%$ reported receiving free health services paid for by the government, while the rest either were paying from personal resource or private insurance As regards to stage of cancer, majority of the respondents $(67.1 \%)$ had stage III and IV (those with advanced stage experience worse symptoms), while $29.9 \%$ had stage I and II. Majority (67.1\%) of the respondents scored high in the symptom scale domain implying that they had worse symptoms.

Table 1. Demographic characteristics of the participants (n $=130)$

\begin{tabular}{|c|c|c|}
\hline Variable & Frequency & Percentage (\%) \\
\hline \multicolumn{3}{|l|}{ Age } \\
\hline $20-30$ & 31 & 23.8 \\
\hline $31-40$ & 47 & 36.2 \\
\hline $41-50$ & 29 & 22.3 \\
\hline 50 and above & 23 & 17.7 \\
\hline Total & 130 & 100 \\
\hline \multicolumn{3}{|l|}{ Marital status } \\
\hline Single & 16 & 12.3 \\
\hline Married & 68 & 52.3 \\
\hline Divorced & 21 & 16.2 \\
\hline Widowed & 25 & 19.2 \\
\hline Total & 130 & 100 \\
\hline \multicolumn{3}{|l|}{ Religion } \\
\hline Christian & 127 & 97.7 \\
\hline Muslim & 3 & 2.3 \\
\hline Total & 130 & 100 \\
\hline \multicolumn{3}{|l|}{ Education status } \\
\hline Non & 1 & 0.7 \\
\hline Primary & 44 & 33.8 \\
\hline Secondary & 45 & 34.6 \\
\hline Tertiary & 40 & 30.7 \\
\hline Total & 130 & 100 \\
\hline \multicolumn{3}{|l|}{ Monthly income } \\
\hline Less than K1000 & 46 & 35.4 \\
\hline K1000-K3500 & 43 & 33.1 \\
\hline K3501-K5000 & 28 & 21.5 \\
\hline K5001 and above & 13 & 10.0 \\
\hline Total & 130 & 100 \\
\hline Total & 130 & 100. \\
\hline
\end{tabular}

Table 3 shows the QoL scores across the domains among the 130 respondents. More than half $(52.3 \%)$ of the respondents scored high on overall QoL. With $47.7 \%$ who scored low/poor on overall QoL. Similarly, high/good scores were obtained for all the five domains of QoL ranging from physical, role, emotional, cognitive and sexual functioning.

Table 4 shows the associations between the demographic characteristics and QoL. Majority of those married (26.9\%) experiences good QoL and those with high income (52.3\%) experience good QoL. Clients with tertiary education experienced poor QoL (18.5\%).

Table 5 shows that social support, type of treatment received, access to health care, and severity condition were all associated with quality of life. For example all the 44 respondents 
who reported to have had inadequate social support scored low/poor [44(33.8\%)] in QoL. On the other hand, two third [86(66.1\%)] of those who reported to have had adequate social support scored high on QoL. Similarly, all the 45 respondents who reported that they have inadequate access to health service, had a poor QoL [45(33.6\%)] with a $p$ value .000 . As regards to the severity of condition, all the 40 (30\%) respondents who had mild symptoms had high QOL, while majority (68 out of 90) of those with worse symptoms [68(52.3)] had low QoL.

Table 2. Patients related factors influencing quality of life (n =130)

\begin{tabular}{|c|c|c|}
\hline Variable & Frequency & Percentage (\%) \\
\hline \multicolumn{3}{|l|}{ Prior knowledge about breast cancer } \\
\hline No knowledge & 28 & 21.5 \\
\hline Little knowledge & 60 & 46.2 \\
\hline Had knowledge & 42 & 32 \\
\hline Total & 130 & 100 \\
\hline \multicolumn{3}{|l|}{ Treatment received } \\
\hline Surgery & 21 & 16.2 \\
\hline Chemotherapy & 87 & 66.9 \\
\hline Radiotherapy & 22 & 16.9 \\
\hline Total & 130 & 100 \\
\hline \multicolumn{3}{|l|}{ Duration of treatment } \\
\hline Less than one month & 33 & 25.4 \\
\hline Between one and six months & 65 & 50 \\
\hline More than six months & 32 & 24.6 \\
\hline Total & 130 & 100 \\
\hline \multicolumn{3}{|l|}{ Access to health care services } \\
\hline Self-pay & 43 & 33.1 \\
\hline Private insurance & 2 & 1.5 \\
\hline Government & 85 & 65.4 \\
\hline Total & 130 & 100 \\
\hline \multicolumn{3}{|l|}{ Stage of cancer } \\
\hline Stage I and II =mild symptoms & 40 & 29.9 \\
\hline Stage III and IV =worse symptoms & 90 & 67.1 \\
\hline Total & 130 & 100 \\
\hline \multicolumn{3}{|l|}{ Severity of disease symptoms } \\
\hline $51-100=$ high/worse symptoms & 90 & 67.1 \\
\hline $1-50=$ low $/$ mild symptoms & 40 & 29.9 \\
\hline Total & 130 & 100 \\
\hline \multicolumn{3}{|l|}{ Support from Family } \\
\hline Worse than before & 3 & 2.3 \\
\hline Still the same & 16 & 12.3 \\
\hline Better & 111 & 85.4 \\
\hline Total & 130 & 100 \\
\hline \multicolumn{3}{|l|}{ Support from Health professional } \\
\hline Poor & 5 & 3.8 \\
\hline Fair & 34 & 26.2 \\
\hline Good & 91 & 70 \\
\hline
\end{tabular}

Table 6 shows the Global Health Status/QoL mean score of 68. Four out of five domains of functional status (Physical, role, cognitive and sexual functioning scored higher than the average global mean score of 68 , while the emotional 60 functioning domain scored (65) below the mean. Conversely, the symptom scale scored high on all the eight sub items of fatigue, nausea and vomiting, pain, dyspnea, insomnia, appetite loss, constipation and diarrhea which signified high symptom experience among respondents. Similarly using the breast cancer supplementary measure (QLQ-BR23), two out of the four functional subscales (body image and sexual functioning) score high than average while sexual enjoyment and future perspectives scored low. On the symptom scale, three (systemic side effects, breast symptoms and arm symptoms) scored higher than averages, signifying high symptom experience. Only the subscale of "upset by symptoms" had a significantly lower score of 18 , indicating that this subsystem was almost not affected for most respondents.

Table 3. Quality of life across the domains $(n=130)$

\begin{tabular}{llll}
\hline Variable & Category & Frequencies & Percentage (\%) \\
\hline \multirow{2}{*}{ Quality of } & low/poor & 62 & 47.7 \\
life & High & 68 & 52.3 \\
& Total & 130 & 100 \\
Physical & $51-100=$ high/good & 104 & 77.6 \\
Functioning & $1-50=$ low/poor & 26 & 19.4 \\
& Missing value & 4 & 3.0 \\
Tole & $51-100=$ high/good & 94 & 100 \\
functioning & $1-50=$ low/poor & 36 & 70.1 \\
& Total & 130 & 26.9 \\
Emotional & $51-100=$ high/good & 85 & 100 \\
functioning & $1-50=$ low/poor & 45 & 63.4 \\
& Total & 130 & 100 \\
Cognitive & $51-100=$ high/good & 114 & 85.1 \\
functioning & $1-50=$ low/poor & 16 & 11.9 \\
& Total & 130 & 100 \\
Sexual & $51-100=$ high/good & 106 & 81.5 \\
functioning & $1-50=$ low/poor & 24 & 18.5 \\
& Total & 130 & 100 \\
\hline
\end{tabular}

\section{Discussion}

The study provided data on QoL of 130 breast cancer patients on treatment in Zambia using the EORTC QLQ-C30 and QLQ-BR23. Overall, only 52.3\% of respondents had high QoL. QoL was high in four out of the five domains which scored above the global mean score of 68 . The present study demonstrates that age, advanced disease, chemotherapy, social support, income, marital status and treatment for breast cancer have significant impact on quality of life of Zambian women with breast cancer. The results of the present study in a Zambian population is consistent with those in Western and Chinese populations which support a universal effect of age, income, marital status, social support, and chemotherapy on the long-term quality of life of breast cancer patients. ${ }^{[19,20]}$

ISSN 1925-4040 E-ISSN 1925-4059 
Table 4. Association between socio-demographic characteristics of the respondents with their Quality of Life

\begin{tabular}{|c|c|c|c|c|c|c|c|}
\hline \multirow{2}{*}{ QoL } & \multicolumn{5}{|l|}{ Age } & \multirow{2}{*}{ Total } & \multirow{2}{*}{$p$-Value } \\
\hline & 20-30yrs & \multicolumn{2}{|c|}{ 31-40yrs } & 41-50yrs & 51 and above & & \\
\hline Low/poor & 23 (17.69\%) & \multicolumn{2}{|c|}{24 (18.46\%) } & $14(10.7 \%)$ & $1(0.76 \%)$ & $62(47.69 \%)$ & \multirow{3}{*}{.023} \\
\hline High/good & $8(6.15 \%)$ & \multicolumn{2}{|c|}{23 (17.69\%) } & 15 (11.3\%) & 22 (16.92\%) & 68 (52.31\%) & \\
\hline Total & $31(23.84)$ & $47(31$. & $5 \%)$ & $29(22.3 \%)$ & 23 (17.69\%) & 130 (100\%) & \\
\hline \multirow{2}{*}{ QoL } & \multicolumn{5}{|c|}{ Marital status } & \multirow{2}{*}{ Total } & \multirow{2}{*}{$p$-value } \\
\hline & Married & \multicolumn{2}{|l|}{ Single } & Divorced & Widowed & & \\
\hline Poor & $33(25.4 \%)$ & \multicolumn{2}{|c|}{$9(6.9 \%)$} & $9(6.9 \%)$ & $11(8.5 \%)$ & \multicolumn{2}{|l|}{$62(47.7 \%)$} \\
\hline Good & 35 (26.9\%) & \multicolumn{2}{|c|}{$7(5.4 \%)$} & $12(9.2 \%)$ & $14(10.77 \%)$ & $68(52.3 \%)$ & \multirow[t]{2}{*}{.460} \\
\hline Total & $68(52.3 \%)$ & $16(12$. & & $21(16.2 \%)$ & 25 (19.2\%) & 130 (100\%) & \\
\hline \multirow{2}{*}{ QoL } & \multicolumn{5}{|c|}{ Level of education } & \multirow{2}{*}{ Total } & \multirow{2}{*}{$p$-value } \\
\hline & Primary & \multicolumn{2}{|c|}{ Secondary } & Tertiary & None & & \\
\hline Poor & $14(10.8 \%)$ & \multicolumn{2}{|c|}{$21(16.2 \%)$} & $24(18.5 \%)$ & $0(0 \%)$ & \multicolumn{2}{|l|}{$62(47.7 \%)$} \\
\hline Good & $30(23.1 \%)$ & \multicolumn{2}{|c|}{$24(18.5 \%)$} & $16(12.3 \%)$ & $1(0.8 \%)$ & 68 (52.3\%) & \multirow[t]{2}{*}{.023} \\
\hline Total & 44 (33.8\%) & 45 (34. & & $40(30.8 \%)$ & $1(0.8 \%)$ & 130 (100\%) & \\
\hline \multirow{2}{*}{ QoL } & \multicolumn{5}{|c|}{ Financial status } & \multirow{2}{*}{$p$-value } & \\
\hline & \multicolumn{2}{|c|}{ Salary $K 3,600$ and above $=$ high } & \multicolumn{2}{|c|}{ Salary Below K3,600 = low } & Total & & \\
\hline Poor & $54(41.5 \%)$ & \multicolumn{3}{|c|}{$8(6.1 \%)$} & $62(47.7 \%)$ & \multirow{3}{*}{.000} & \\
\hline High & $68(52.3 \%)$ & \multicolumn{3}{|c|}{$0(0 \%)$} & $68(52.3 \%)$ & & \\
\hline Total & $122(93.8 \%)$ & \multicolumn{3}{|c|}{$8(6.1 \%)$} & $130(100)$ & & \\
\hline
\end{tabular}

Table 5. Association between social, professional support and clinical characteristics of the respondents with their quality of life

\begin{tabular}{|c|c|c|c|c|c|}
\hline \multirow{2}{*}{ QoL } & \multicolumn{2}{|l|}{ Social support } & \multirow{2}{*}{ Total } & \multirow{2}{*}{$p$-Value } & \\
\hline & $1-50=$ inadequate & $51-100=$ adequate & & & \\
\hline Low/poor & $44(33.8 \%)$ & $18(13.8 \%)$ & $62(47.7 \%)$ & & \\
\hline High & $0(0 \%)$ & $68(52.3 \%)$ & $68(52.3 \%)$ & .000 & \\
\hline Total & $44(33.8 \%)$ & $86(66.1 \%)$ & $130(100 \%)$ & & \\
\hline \multirow{2}{*}{ QoL } & \multicolumn{3}{|c|}{ Support from health care professionals } & \multirow{2}{*}{ Total } & \multirow{2}{*}{$p$-Value } \\
\hline & Poor & Fair & Good & & \\
\hline Low/poor & $2(1.5 \%)$ & $20(15.4 \%)$ & $40(30.0 \%)$ & $62(47.7 \%)$ & \\
\hline High & $3(2.3 \%)$ & $14(10.8 \%)$ & $51(39.2 \%)$ & $68(52.3 \%)$ & .345 \\
\hline Total & $5(3.8 \%)$ & $34(26.2 \%)$ & $91(70.0 \%)$ & $130(100 \%)$ & \\
\hline \multirow{2}{*}{ QoL } & \multicolumn{3}{|l|}{ Treatment received } & \multirow{2}{*}{ Total } & \multirow{2}{*}{$p$-Value } \\
\hline & Chemotherapy & Radiotherapy & Surgery & & \\
\hline Low/poor & $56(43.1 \%)$ & $2(1.5 \%)$ & $4(3.1 \%)$ & $62(47.7 \%)$ & \\
\hline High & $31(23.8 \%)$ & $20(15.4 \%)$ & $17(13.1 \%)$ & $68(52.3 \%)$ & .023 \\
\hline Total & $87(66.9 \%)$ & $22(16.9 \%)$ & $21(16.2 \%)$ & $130(100 \%)$ & \\
\hline \multirow{2}{*}{ QoL } & \multicolumn{3}{|l|}{ Access to health services } & \multirow{2}{*}{$p$-Value } & \\
\hline & Below 40 = inadequate & $40-100=$ adequate & Total & & \\
\hline Low/poor & $45(33.6 \%)$ & $17(13.1 \%)$ & $62(47.7 \%)$ & & \\
\hline High & $0(0 \%)$ & $68(52.3 \%)$ & $68(52.3 \%)$ & .000 & \\
\hline Total & $45(33.6 \%)$ & $85(63.4 \%)$ & $130(100 \%)$ & & \\
\hline \multirow{2}{*}{ QoL } & \multicolumn{2}{|l|}{ Severity of the condition } & \multirow{2}{*}{ Total } & \multirow{2}{*}{$p$-Value } & \\
\hline & Below $40=$ mild symptoms & $40-100=$ worse symptoms & & & \\
\hline Low/poor & $0(0 \%)$ & $68(52.3 \%)$ & $68(52.3 \%)$ & \multirow{3}{*}{.000} & \\
\hline High & $40(30.0 \%)$ & $22(16.9 \%)$ & $62(47.7 \%)$ & & \\
\hline Total & $40(30.0 \%)$ & $90(67.1 \%)$ & $130(100 \%)$ & & \\
\hline
\end{tabular}


Table 6. Breast cancer patients' functioning and global quality Of life scores as measured by the EORTCQLQ-C30*

\begin{tabular}{|c|c|c|c|c|}
\hline Scale & Numberof items & Item range & C30-q Item numbers & Mean Score \\
\hline \multicolumn{5}{|l|}{ Global health status/QoL } \\
\hline Global health status/QoL $(\mathrm{n}=130)$ & 2 & 6 & 29,30 & 68 \\
\hline \multicolumn{5}{|l|}{ Functional scales } \\
\hline Physical functioning $(\mathrm{n}=130)$ & 5 & 3 & 1 to 5 & 80 \\
\hline Role functioning $(\mathrm{n}=130)$ & 2 & 3 & 6,7 & 72 \\
\hline Emotional functioning $(\mathrm{n}=130)$ & 4 & 3 & 21 to 24 & 65 \\
\hline Cognitive functioning ( $\mathrm{n}=130$ ) & 2 & 3 & 20,25 & 114 \\
\hline Social functioning $(\mathrm{n}=130)$ & 2 & 3 & 26,27 & 103 \\
\hline \multicolumn{5}{|l|}{ Symptom scales/items } \\
\hline Fatigue $(\mathrm{n}=130)$ & 3 & 3 & $10,12,18$ & 99 \\
\hline Nausea and vomiting $(\mathrm{n}=130)$ & 2 & 3 & 14,15 & 107 \\
\hline Pain $(n=130)$ & 2 & 3 & 9,19 & 93 \\
\hline Dyspnea $(\mathrm{n}=130)$ & 1 & 3 & 8 & 113 \\
\hline Insomnia $(\mathrm{n}=130)$ & 1 & 3 & 11 & 102 \\
\hline Appetite loss $(n=130)$ & 1 & 3 & 13 & 103 \\
\hline Constipation $(n=130)$ & 1 & 3 & 16 & 112 \\
\hline Diarrhea $(\mathrm{n}=130)$ & 1 & 3 & 17 & 116 \\
\hline Financial difficulties $(n=130)$ & 1 & 3 & 28 & 89 \\
\hline Functional scales & & & BR23-q Item numbers & \\
\hline Body image $(n=130)$ & 4 & 3 & $39-42$ & 90 \\
\hline Sexual functioning ( $\mathrm{n}=130$ & 2 & 3 & 44,45 & 106 \\
\hline Sexual enjoyment $(n=59)$ & 1 & 3 & 46 & 14 \\
\hline Future perspective $(\mathrm{n}=130)$ & 1 & 3 & 43 & 57 \\
\hline \multicolumn{5}{|l|}{ Symptom scales/items } \\
\hline Systemic therapy side effects $(n=130)$ & 7 & 3 & $31-34,36,37,38$ & 87 \\
\hline Breast symptoms $(n=130)$ & 4 & 3 & $50-53$ & 108 \\
\hline Arm symptoms $(\mathrm{n}=130)$ & 3 & 3 & $47-49$ & 107 \\
\hline Upset by hair loss $(\mathrm{n}=103)$ & 1 & 3 & 35 & 18 \\
\hline
\end{tabular}

*CQ30-q = question number in the core questionnaire; BR23-q = question number in the breast cancer questionnaire; *High Scores under the Functional Scales denotes high QoL; High Scores under Symptoms Scales denotes worse Symptoms/Poor QoL.

Respondents less than 40 years $(52 \%)(p=.023)$ experiences poor quality of life. Single ladies also experienced poor quality of life and social domain was more impaired. This shows that younger age group felt more social inhibitions when diagnosed with and while undergoing treatment for breast cancer, especially post-mastectomy as compared to older age group. Younger patients were more concerned about their future too. This is similar to a study that was conducted by Sharma and Purkayastha ${ }^{[21]}$ in India that found that the young (30-39 years) breast cancer survivors showed significantly worse QoL outcomes compared with older age groups in relation to physical functioning $(p=.0003)$, social functioning ( $p=0.0313)$, sexual functioning ( $p=.000)$, and future perspective $(p=.029)$. Though in a similar study by Bantema-Joppe et al. ${ }^{[22]}$ they found that the development of role, emotional, and cognitive functioning over time of the oldest age group differed from the two younger age groups (role functioning $p<.001$; emotional functioning $p=.010$, and cognitive functioning $p<.001$ ), with a trend towards better outcomes in the younger group and worse outcomes in the oldest age group. ${ }^{[23]}$

From the present study, respondents with advanced stage of disease (stage III \& IV), 67\% experienced severe symptoms and performed worse or had poor QoL as compared to those with early disease. Oates et al. ${ }^{[24]}$ in their study in oropharyngeal cancer patients also found that deterioration in most domains was most frequent for stage III/IV patients. These results are similar to our study, indicating advanced stages of disease lead to worse QoL in cancer patients. ${ }^{[21]}$ The present study shows that high household income is associated with a better QoL of patients with breast cancer in each and every domain measured. Our findings are consistent with those of

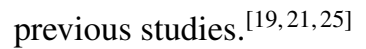

The present study also revealed other factors that had significant association with QoL. Among these includes; 
chemotherapy treatment which was associated with lower score of overall QoL measure $(p=.023)$, possibly related to its toxicity and severe side-effects. ${ }^{[19,21]}$ Another factor was social support, where those who adequate social support had good QoL ( $p$-Value .000), implying that there is an association between QoL and social support. ${ }^{[21,26]}$ Furthermore, accesses to adequate health care were associated with QoL ( $p$-value .000) as those who had adequate social had good QoL. ${ }^{[27]}$

\section{Conclusion}

In summary, the present study demonstrates that there is a close relationship between clinical and socio-demographic factors and the QoL in patients with breast cancer. High household income, adequate social support and access to health services significantly and independently improve QoL of Zambian women with breast cancer. The study also con- cludes that problems with sexual, emotional, functional and role functioning are common among breast cancer undergoing chemotherapy and/or surgery (total mastectomy) due to the side effects and impaired body image experienced. Considering that diagnosis of breast cancer and its treatment affects several facets of a woman's life ranging from physical, emotional, social and financial aspects consequently affecting the entire QoL. Therefore any intervention aimed at improving the QoL should be multidimensional.

\section{ACKNOWLEDGEMENTS}

We thank the participants for the role they played in providing valuable data for the successful completion of the study.

\section{CONFLICTS OF INTEREST Disclosure}

The authors have not declared no conflict of interests.

\section{REFERENCES}

[1] Montazeri A, Gillis CR, McEwen J. Measuring quality of life in oncology: is it worthwhile? Part II. Experiences from the treatment of cancer. Eur J Cancer Care. 2010; 5: 168-175. PMid:9117051 https://doi.org/10.1111/j.1365-2354.1996.tb00229.x

[2] Ferlay J, Soerjomataram I, Ervik M, et al. GLOBOCAN 2012 v1.0: Cancer Incidence and Mortality Worldwide: IARC Cancer Base No. 11. International Agency for Research on Cancer. 2013.

[3] Alzabaidey FJ. Quality of Life Assessment for Patients with Breast Cancer Receiving Adjuvant Therapy. J Cancer Sci Ther. 2012; 4: 051-055.

[4] Le Y, Gao Z, Gomez LS, et al. Acculturation and Adherence to Physical Activity Recommendations Among Chinese American and Non-Hispanic White Breast Cancer Survivors. Journal of Immigrant and Minority Health. 2018; 21(1): 80-88. PMid:29569102 https://doi.org/10.1007/s10903-018-0721-x

[5] Ministry of Health. Lusaka Provincial Health Office, Annual Health Statistical Bulletin. Lusaka: Ministry of Health. 2012.

[6] Cancer Diseases Hospital (2012). Action plan.

[7] Mukwato KP, Mweemba P, Makukula MK, et al. Stress and Coping Mechanisms among Breast Cancer Patients and Family Caregivers: A Review of Literature: Medical Journal of Zambia. 2010.

[8] The WHOQOL Group. The World Health Organization Quality of Life assessment (WHOQOL): position paper from the World Health Organization. Soc. Sci. Med. 1999a; 41: 1403. https: //doi.org/10.1016/0277-9536(95)00112-K

[9] Ibrahim Y, Umut V, Ahmet A. Assessment of the Quality of Life In Turkish Breast Cancer Patients. 2014.

[10] Grimmett AL. The Experience of Survivorship: Quality of Life of African American Breast Cancer Survivors. 2016. Accessed from: http://scholarworks. waldenu.edu/dissertations

[11] Mwiinga-Kalusopa V, Ngoma C, Lishimpi K. Health related quality of life among breast cancer patients with unilateral arm lymphedema at cancer diseases hospital in Lusaka, Zambia; Journal of Cancer Research and Experimental Oncology. 2016. Available from: http://www .academicjournals . org/JCREO
[12] Groenvold M. Health-related quality of life in early breast cancer Dan Med Bull. 2010; 57(9): B4184.

[13] Zou Z, McCoy P. Quality of women among women with breast cancer living in Wuhan, China. 2014. Accessed from https://doi.or $\mathrm{g} / 10.1016 / \mathrm{j} \cdot \mathrm{ijnsson} 12 / 03 / 18 \mathrm{at} 22: 00 \mathrm{hrs}$

[14] Pandey M, Singh SP, Behere PB, et al. Quality of life in patients with early and advanced carcinoma of the breast. Eur J Surg Oncol. 2005; 26: 20-24. PMid:10718174 https://doi.org/10.1053/ejso.1 999.0734

[15] Rahou BH, El Rhazi K, Ouasmani F, et al. Quality of life in Arab women with breast cancer: a review of the literature. $2016 \mathrm{Apr} 27$.

[16] Hewitt M, Greenfield S, Stovall E. From cancer patient to cancer survivor: Lost in transition. The National Academies Press. Washington, D.C. 2005.

[17] Machin D, Campbell MJ. Design of Studies for Medical Research. John Willey \& Sons Ltd, Singapore. 2005.

[18] Montezeri A, Harirchi I, Vahdani M, et al. The EORTC breast cancerspecific quality of life questionnaire (EORTC QLQ-BR23): Translation and validation study of the Iranian version. Qual Life Res. 2000; 9: 177-184. PMid:10983481 https://doi.org/10.1023/A:10 08918310251

[19] Yan B, Yang LM, Hao LP, et al. Determinants of Quality of Life for Breast Cancer Patients in Shanghai, China. PLoS ONE. 2016; 11(4): e0153714. PMid:27082440 https://doi.org/10.1371/journa 1.pone. 0153714

[20] Ahles TA, Saykin AJ, Furstenberg CT, et al. Quality of life of longterm survivors of breast cancer and lymphoma treated with standarddose chemotherapy or local therapy. J Clin Oncol. 2005; 23: 4399405. PMid:15994149 https://doi.org/10.1200/JC0.2005.0 3.343

[21] Sharma N, Purkayastha A. Factors affecting quality of life in breast cancer patients: A descriptive and cross-sectional study with review of literature. 2017; 8(2): 75-83. PMid:28706408 https: //doi.org/10.4103/jmh. JMH_15_17

[22] Bantema-Joppe EJ, de Bock GH, Woltman-van M, et al. The impact of age on changes in quality of life among breast cancer survivors 
treated with breast-conserving surgery and radiotherapy. Br J Cancer. 2015; 112: 636-43. PMid:25602967 https://doi.org/10.1038/ bjc. 2014.632

[23] Cimprich B, Ronis DL. Attention and symptom distress in women with and without breast cancer. Nurs Res. 2001; 50: 86-94 PMid:11302297 https://doi.org/10.1097/00006199-20010 3000-00004

[24] Oates J, Davies S, Roydhouse JK, et al. The effect of cancer stage and treatment modality on quality of life in oropharyngeal cancer. Laryngoscope. 2014; 124: 151-8. PMid:23918289 https: //doi.org/10.1002/lary.24136
[25] Al-Naggar RA, Nagi NM, Ali MM, et al. Quality of Life among Breast Cancer Patients in Yemen. Asian Pac J Cancer Prev. 2011; 12 : 2335-41.

[26] Bonsu AB, Aziato L, Nat JA, et al. Living with Advanced Breast Cancer among Ghanaian Women: Emotional and Psychosocial Experiences, Kumasi, Ghana. 2014. https : //doi . org/10.1155/20 $14 / 403473$

[27] Lôbo1 SA, Carvalho AF, De Almeida PC, et al. Quality of life in women with breast cancer undergoing chemotherapy, Ana Fátima Carvalho Fernande Alexandre Baraúna street, 1115, Fortaleza, CE, Brazil. Zip Code: 60430-160. 2014. 